\title{
Domestic spaces design for allow income housing
}

\author{
Coppelia Herran Cuartas \\ Universidad Pontificia Bolivariana | Colombia | coppelia.herran@upb.edu.co
}

\begin{abstract}
This research is related to the urban transformation that Medellín underwent during the 2004-2011 administrations, in which large architectural projects were implemented in the poorest and most violent areas of the city. To inquire about the effectiveness of these interventions, we look at one of the housing projects worthies of different international recognitions, called the Housing Consolidation of the Quebrada Juan Bobo. Characterized by generating Social Interest Housing -(Vivienda de Interés Social-VIS in Spanish)- in the creek's basin, this project benefited 1,240 people who were relocated within the same neighborhood, including some on the same space next to the creek, where their old home was built.
\end{abstract}

Keywords: live; quality of life; home; domestic practices; informality.

\section{INTRODUCCIÓN}

Durante la última década, Medellín ha obtenido una serie de reconocimientos por su modelo de gestión urbana basado en un discurso de ciudad educada, incluyente e innovadora. De acuerdo con ISVIMED (2014), la ciudad pasó de ser una de las más peligrosas y violentas del mundo, debido al fenómeno del narcoterrorismo entre 1980 y 2000 , para transformarse a partir de la innovación, en una ciudad modelo de resiliencia y urbanismo. Medellín, al igual que otras ciudades de Latinoamérica, ha experimentado procesos migratorios del campo a la ciudad por motivos de violencia u oportunidades laborales, lo cual ha incidido fuertemente en su crecimiento poblacional y explosión demográfica.

De acuerdo con Naranjo (1992), entre 1950 y 1970 muchas familias migraron a Medellín, en busca de mejores oportunidades socioeconómicas. Sin embargo, un acceso restringido a la tierra las llevó a asentarse en zonas periféricas de la ciudad, para autoconstruir sus viviendas por fuera del ordenamiento oficial de la época. Frente a esta creciente demanda de vivienda, Eslava (2017) afirma que la solución fue encontrada en los denominados barrios de invasión y urbanizaciones piratas, situadas en las laderas de altas pendientes a lo largo de las cuencas de ríos y quebradas. Con viviendas autogestionadas, informales y autoconstruidas, estas familias se asentaron en terrenos inestables y desprovistos de accesibilidad a servicios públicos, infraestructura y espacio público, lo cual acentuó procesos de segregación urbana de orden físico, social y económico. Esta "otra ciudad", denominada así por Martin (2012), fue construida en gran parte sin planeación urbana y ambiental. Para el autor, la "otra ciudad" se convirtió en el resultado de un patrón excluyente de desarrollo, planeamiento y gestión urbana de mercados de tierra, cuyos sistemas políticos y jurídicos no ofrecían condiciones propias de accesos al suelo ni vivienda para la población más vulnerable y de más bajos recursos (Martin, 2012).
Para Eslava (2017), esta otra ciudad informal y autoconstruida ubicada especialmente en las zonas norte, centroriental y centroccidental de Medellín, desencadenó una serie de procesos endógenos que marcaron altos índices de violencia, baja calidad de vida y de desarrollo humano, a diferencia de la Medellín formal y planeada. De acuerdo con Pérez (2010) es en la década de los 90 en la que Medellín llega a su pico de muertes violentas, durante la administración de Luis Alfredo Ramos 1992-1994 con 16.249 homicidios, al tiempo que la economía del narcotráfico se infiltraba hacia las organizaciones del Estado y en la vida de las élites y las clases populares por igual. La entrada de dineros rápidos provenientes del tráfico de drogas aumentó la captación de grupos poblacionales para el desarrollo de actividades delictivas, mientras la violencia, la conformación de bandas delincuenciales, el secuestro y la impunidad, crecían con efectos diferenciales en las zonas nororiental, noroccidental y centro-occidental (Alcaldía de Medellín, 2011 a).

Para empezar a saldar la histórica deuda social, la Alcaldía de Medellín comienza a reconocer la marcada desigualdad entre los años 2004 y 2011 respecto al desarrollo de sus territorios, en especial en las comunas de la ladera nororiental, la noroccidental y los barrios de ocupación indebida, donde se detectaron los indicadores de desarrollo humano más bajos de la ciudad. Para lograr un mejoramiento de las condiciones de vida de las personas, luchar contra la pobreza y la segregación, la Administración toma como referente las condiciones de estos sectores, valiéndose de una serie de indicadores tales como el Índice de Desarrollo Humano (IDH), el Índice de Calidad de Vida (ICV), el índice de población por Estrato y el de homicidios por comunas, para intervenir las periferias urbanas con los indicadores más altos de población y taza de homicidios (EDU, 2015).

De esta forma el Estado y la Alcaldía de Medellín llevan a cabo una trasformación física en diferentes zonas de la ciudad, con el objetivo de mejorar la calidad de vida en cuanto a bienestar, equidad, oportunidades y desarrollo 
social de sus habitantes. Como una estrategia de intervención que buscaba conectar los asentamientos informales a la dinámica formal de la ciudad, la Administración Municipal (Alcaldía de Medellín, 2011 a) destina grandes recursos hacia los sectores más vulnerables, para llevar a cabo un gran número de obras arquitectónicas durante las Administraciones 2004-2011.

Para promover el encuentro ciudadano y enfrentar esta problemática multidimensional, se construyen numerosos equipamientos educativos, recreativos, culturales, institucionales, deportivos, de transporte, salud y vivienda. Estas transformaciones hacen que Medellín se convierta en un laboratorio de innovación urbana y gestión pública, que la llevaron a recibir premios y reconocimientos como la ciudad más innovadora en el 2013, además de ser elegida como anfitriona del VII Foro Urbano Mundial promovido por ONU Hábitat en 2014, y centrar la atención sobre temas de desarrollo urbano sostenible y vivienda adecuada a nivel global (Navarrete, 2014), después de ser reconocida como la ciudad más violenta del mundo (Alcaldía de Medellín, 2007).

\section{REFERENTE EMPÍRICO}

Con el objetivo de reflexionar sobre los alcances que ha tenido este modelo de intervención territorial que buscó reducir la brecha social de algunos sectores de la ciudad, transformando diferentes territorios por medio de la arquitectura y el urbanismo para mejorar la calidad de vida de las personas, centro mi análisis en uno de los programas más emblemáticos del plan de mejoramiento de barrios, que corresponde al proyecto de viviendas de la consolidación habitacional de la Quebrada Juan Bobo, ubicado en la comuna 2 y merecedor del Premio de Hábitat Dubái 2008 de Mejores Prácticas.

De acuerdo con la institucionalidad, el objetivo de este proyecto fue, al igual que el resto de las intervenciones de estas Administraciones, mejorar la calidad de vida de la población asentada en este sector, e incorporar los barrios informales al tejido urbano de la ciudad con corredores de movilidad, centralidades barriales, conexión mediante puentes, viaductos y redes peatonales entre microterritorios (Alcaldía de Medellín, 2011a). Sobre la intervención específica en la quebrada de Juan Bobo, las entidades gubernamentales establecieron, a partir de un diagnóstico elaborado con el Plan Urbano Integral (PUI) de la zona nororiental, que los tramos de esta quebrada representaban las peores condiciones de habitabilidad. Por esta razón, la Empresa de Desarrollo Urbano (EDU) decide de forma participativa y concertada con la comunidad, intervenir la parte baja y media de la quebrada definida por las carreras 41B y $49 \mathrm{~B}$ y las calles 106 y 107 de los Barrios Andalucía y Villa Niza de la Comuna 2 y Santa Cruz en la zona nororiental. Una de las características físicoespaciales de este polígono de intervención era un área de $22.885 \mathrm{~m}^{2}$, resultante de un proceso de ocupación de carácter invasivo, que provocó la progresiva desaparición de zonas verdes. El poco espacio público existente en ese momento se limitaba a un sistema de senderos precarios y desarticulados, además de una serie de espacios naturales que, por sus características topográficas, imposibilitaba la ocupación por medio de viviendas.

De acuerdo con las entidades estatales, los problemas habitacionales más representativos de este sector estaban asociados con la ocupación de la quebrada en la que se evidenció un fuerte hacinamiento, presencia de viviendas en zonas de riesgo, construcciones inadecuadas, condiciones espaciales y estructurales muy deficientes, poca salubridad y conexiones fraudulentas de servicios públicos, lo que llevó a tomar acciones para la intervención en los barrios Villa Niza y Andalucía, sobre la Quebrada Juan Bobo.

En este sentido, la EDU establece que uno de los principios esenciales de esta propuesta fue la reubicación de la comunidad en el mismo sitio, para evitar desalojos y expropiaciones a las familias que habitaban en el borde de la quebrada y en las zonas de alto riesgo. Para esto se generó una consolidación habitacional a lo largo de la quebrada Juan Bobo, constituida por 12 edificios entre 5 y 9 pisos, bajo el formato de Vivienda de Interés Social (VIS); además de realizar la recuperación ambiental de la quebrada, e implementar mejoras en los accesos y en los senderos del sector (EDU, 2015).

Al indagar por el impacto social que trajo este cambio urbanístico en los modos de habitar de la comunidad que antes vivía de manera informal en la quebrada, surge la pregunta sobre cuáles fueron los encuentros y desencuentros que experimentaron las personas desde su habitar, dentro de este formato de Vivienda de Interés Social.

Para dar respuesta a esta cuestión, esta investigación se concentró analizar las soluciones que estableció el Estado frente al déficit habitacional y conocer las dimensiones sociales y materiales, que confluyen en este tipo de espacios. Pensados para grupos familiares que tanto el municipio como sus diseñadores consideran homogéneos y con necesidades similares, se indagó por las diferentes configuraciones y percepciones que identificaron sus moradores, con relación a la vivienda formal.

Aunque los problemas del habitar y vivienda en la construcción de ciudad han sido objeto de estudio desde tiempo atrás desde diversas disciplinas, se evidenció que la mayoría de los trabajos locales se han concentrado en analizar la transición y cambio de vivienda informal a la vivienda formal otorgada por el Estado; tal y como se demuestra en trabajos como los de Cardona (2014) y Peláez (2013). La tendencia más fuerte en este tipo de investigaciones tiene como referente empírico la reubicación de los habitantes del "Morro de Basuras" de Moravia en el Marco del Programa de Intervención Integral de Moravia y su área de influencia, hacia proyectos habitacionales como Ciudadela Nuevo Occidente, El Limonar, La Herradura y el Sector Los Álamos.

Aparte de analizar el lugar planificado desde el diseño de vivienda y el lugar practicado por sus habitantes, estas investigaciones revisan situaciones asociadas con el bienestar que experimenta la comunidad en la nueva forma de habitar (Cardona, 2014), así como los problemas de desarraigo y falta de cohesión social (Peláez, 2013). Otros trabajos analizan las formas de apropiación que se vienen dando en el nuevo espacio arquitectónico (Sanín, 2008) y la tensión que surge frente a los patrones culturales que trae consigo cada población, dando como resultado una serie de conflictos en la convivencia, al interior de la población reubicada en zonas de expansión urbana de desarrollo incompleto, con vivienda masiva en altura 
(Mena, 2011). En esta misma línea, se encuentran otros trabajos que muestran el problema generado al omitir el componente cultural de las formas de vida de las comunidades reasentadas y las dificultades que éstas empiezan a enfrentar, por el establecimiento de nuevas normas y responsabilidades económicas que implica la tenencia de una vivienda formal (Bárcenas, 2015).

Todos estos trabajos coinciden en reconocer que los proyectos residenciales tuvieron la responsabilidad de reubicar a una población en estado de riesgo, con el objetivo de reducir la vulnerabilidad física en asuntos como la tenencia de la vivienda, la confiablidad tecnológica y la salubridad de la morada como aspectos que inciden en la salud física y mental de las personas. Si bien es cierto que todas las investigaciones ponen en evidencia la mejora del hábitat en términos cuantitativos, se identifica una tendencia relacionada con la condición de vulnerabilidad social que experimentan los receptores de vivienda nueva, por temas de convivencia y dificultades para asimilar los nuevos patrones de comportamiento que exige la vivienda formal. A estas situaciones se suma que, tanto la localización espacial en la periferia como la tipología de vivienda en altura, generaran nuevas formas de organización socioespacial, económica y cultural ajenas a las existentes en el lugar de origen, dando lugar a la pérdida de los lazos sociales, familiares y económicos que se suman a procesos de adaptación forzada.

\section{METODOLOGÍA}

Con la necesidad de conocer los criterios que estableció la Institucionalidad para ejecutar este proyecto habitacional, analizar la entrega y funcionamiento del mismo como producto arquitectónico, e indagar por la percepción que tienen los habitantes de este proyecto habitacional, decidí apoyarme en teorías como La trialéctica del espacio de Lefebvre (2013) para profundizar en el análisis socioespacial a partir de tres dimensiones denominadas espacio concebido, percibido y vivido en los que se integran elementos físicos, mentales y sociales. El espacio vivido o el espacio de las experiencias de Lefevbre, es complementado con la perspectiva que asume Soja (2014), retomando los postulados de Lefebvre para desarrollar cuestiones relativas a las prácticas espaciales que se dan en un determinado espacio y las representaciones simbólicas que se producen en torno a él, para superar la dialéctica del espacio y formular de manera holística, una triada espacial que tiene como nodo articulador la propuesta conceptual del "Thirdspace" (Soja, 1969). Este tercer espacio o espacio de las representaciones, se relaciona con la dimensión de lo imaginado y lo simbólico, qué a su vez se articula con el concepto de Topofilia propuesto por Tuan (2007), para poner en consideración los vínculos afectivos que tiene el ser humano con un entorno material. En este último, el autor explica los afectos y sentimientos que se pueden desarrollar hacia un sitio específico como puede ser la vivienda, el trabajo o un espacio público que se dota de significado.

Para conocer los aspectos relevantes que tuvieron en cuenta las instituciones locales del Estado, para mejorar la calidad de vida de la comunidad receptora de vivienda nueva y la manera cómo estos han venido configurando la nueva forma de habitar, diseñé una investigación de carácter cualitativo entendiendo que los hallazgos que se produjeron en este trabajo no se lograron a través de procedimientos estadísticos, u otros medios cuantificación.

El argumento de la elección de una investigación cualitativa se apoya en el enfoque de Strauss y Corbin (2002) sobre el análisis interpretativo que permite indagar sobre la vida de las personas, su propia experiencia, comportamientos, sentimientos y emociones. Además, añaden que el análisis cualitativo no corresponde a la cuantificación de los datos cualitativos, sino al proceso no matemático de interpretación realizado con el propósito de descubrir conceptos y relaciones en los datos brutos, que luego se organizan en un esquema explicativo teórico.

Debido a que esta investigación buscó comprender el significado o naturaleza de la experiencia de una comunidad a la que se le entregó vivienda nueva con el fin de mejorar su calidad de vida, fue necesario centrarme en las acciones de observación, razonamiento inductivo y el descubrimiento de nuevos conceptos dentro de una perspectiva holística (Quintana y Montgomery, 2006) que me permitieran conocer los aspectos más particulares que resultan de un proceso histórico de construcción, a partir de la lógica y el sentir de sus protagonistas (Pérez, 2001, citado por Quintana y Montgomery, 2006, p. 48). Para examinar de cerca los significados que los protagonistas les atribuyen a las acciones que resultaron con el cambio de su vivienda, fue necesario recurrir a la etnografía como enfoque, para abordar el estudio de comunidades y relaciones sociales. En este sentido, Goetz \& LeCompte (1988) explican que la descripción de la vida cotidiana de las personas permite reconstruir los escenarios y grupos culturales particulares, dentro de un marco interpretativo comprensible.

El empleo de la etnografía como enfoque y no como método, se hizo con la intensión de presentar episodios como porciones de la vida de las personas investigadas y documentarlos con un lenguaje natural que representara de la manera más fiel, la forma en que se sienten las personas, lo que saben, lo que conocen, así como sus creencias, percepciones, modos de ver y entender (Guba, 1978).

En su triple acepción de enfoque, método y texto, Guber (2014) señala que la etnografía permite la concepción y práctica de un conocimiento que ayuda a comprender los fenómenos sociales desde la perspectiva de sus miembros entendidos como actores, agentes, o sujetos sociales a quienes, en el caso de esta investigación, corresponde a los receptores de los apartamentos ubicados en la consolidación habitacional de Juan Bobo. Según Runciman (1983, citado en Guber, 2014), la especificidad de este enfoque corresponde a la descripción o comprensión terciaria que se ocupa desde la perspectiva de sus agentes. Esta descripción para Guber (2014) funciona por medio de la posibilidad de no malinterpretar los agentes, es decir, al no incurrir en interpretaciones etnocéntricas, sustituyendo su punto de vista, valores y razones por el del investigador. Como método abierto de investigación en el que caben las encuestas, las técnicas no directivas, la observación participante, las entrevistas no dirigidas y la residencia prolongada con los sujetos de estudio, Guber reconoce a la etnografía como un conjunto de actividades que tiene la relevancia más representativa en el trabajo de campo, ya que es en ese espacio donde tiene escena la práctica de la observación, se condensa la 
experiencia y se actualiza y reactualiza constantemente el problema de investigación.

Para llevar a cabo este proceso se tuvieron en cuenta las siguientes fases:

1. Preparación del trabajo de campo: En este primer momento se diseñaron y ajustaron los instrumentos, con el fin de recolectar datos provenientes de los actores de interés para esta investigación. Se efectuaron búsquedas de contactos en entidades institucionales como la Empresa de Desarrollo Urbano EDU, la Alcaldía de Medellín y el Centro de Estudios Urbanos y Ambientales URBAM. El énfasis estuvo orientado a identificar actores institucionales y especialistas que participaron de forma directa o indirecta en la transformación de la zona de influencia del Metrocable, con el PUI de la zona nororiental y la consolidación habitacional Juan Bobo.

El segundo paso en el trabajo de campo, se concentró en el diseño de una guía de entrevista semiestructurada que respondiera a asuntos específicos de las personas, con relación a sus viviendas y el proyecto habitacional, además de la generación de un diario de campo y un directorio en el que se llevó el registro de personas, organizaciones e instituciones asociadas al tema de la investigación, además de hacer el primer diseño categorial deductivo, con el software Atlas-ti, para registrar y codificar la información recolectada. Este programa es un potente conjunto de herramientas para el análisis cualitativo de grandes cuerpos textuales, gráficos y de video que permite organizar, reagrupar y gestionar todos los datos de campo recolectados y organizarlos de forma sistémica.

2. Trabajo de campo: Durante esta fase, se establecieron los primeros contactos con los actores sociales relacionados con los objetivos de investigación. Estos perfiles estuvieron definidos por un primer grupo conformado por 12 agentes institucionales relacionados con el diseño y ejecución de la consolidación habitacional; y un segundo grupo de agentes, estuvo asociado con las personas que recibieron vivienda nueva y que actualmente habitan en estos edificios. Las principales actividades realizadas en esta fase estuvieron dirigidas a elaborar un inventario de fuentes primarias que permitiera seleccionar los actores claves que servirían para indagar, por medio de entrevistas y visitas en sus viviendas en los barrios Villa Niza, Villa del Socorro y Andalucia, donde se encuentra ubicada la consolidación habitacional.

3. Selección de la muestra: Es importante aclarar que este estudio no buscó poner su foco en la representatividad, sino avanzar en profundidad y que el número de interlocutores total (26 personas en este caso), determinado por la saturación de la información y la limitación de tiempo y recursos económicos. Con el objetivo de incluir tantos puntos de vista como tipos de personas que participaron en la muestra dentro del espacio vivido, se buscaron interlocutores que, además de ser propietarios de estos apartamentos, vivieran en ellos. La idea era, entre otras cosas, conocer las diversas formas de vida que experimentaban las personas en este formato habitacional y revisar con ellas, las promesas que estableció la institucionalidad para mejorar su calidad de vida, a partir de la solución de déficit habitacional. Para esto se empleó el muestreo por conveniencia o selectivo, que, de acuerdo con Mejía (2000) consiste en la selección de unidades para la muestra de forma arbitraria sin criterio alguno que lo defina, ya que su elección dependerá de la disponibilidad que tengan las personas, tal y como ocurrió con los habitantes de estos apartamentos. El tiempo en este caso fue un factor importante que afectó la concreción de las entrevistas, ya que muchos de los interlocutores tenían ocupaciones domésticas, trabajos por fuera de la casa, cuidado de los hijos y nietos, o compromisos con otras personas y no podían dedicar el tiempo que requerían estas entrevistas.

4. Recolección de los datos: Como parte del método etnográfico se incluyeron las siguientes técnicas para la recolección y análisis de datos que se muestra a continuación.

\section{- Registro de notas en un diario de campo.}

- Observación activa en una ludoteca ubicada en el bloque 8, para conocer las experiencias del ámbito doméstico y el entorno vecinal.

-Observación simple en campo dentro del contexto de vivienda con visitas a los 12 edificios, zonas comunes y el barrio en general.

-Realización de 40 entrevistas informales y 35 formales por medio de entrevistas semi-estructuradas abiertas a profundidad dirigidas a habitantes, vecinos y agentes institucionales relacionados con el proyecto habitacional.

-Recolección de imágenes digitales y audios en los apartamentos y barrios analizados, para captar la cotidianidad de los habitantes y vecinos.

-Sistematización de los datos recolectados a través del software Atlas-ti.

5. Cierre del trabajo de campo: En esta última fase, se completó el registro y la sistematización de la información recolectada, además de regresar al campo para hacer una lista de contra chequeo en la que se realizaron las últimas entrevistas, para resolver dudas que emergieron durante el proceso de análisis de los datos, con las categorías definidas. Las actividades realizadas en esta fase se enfocaron en terminar de ingresar entrevistas transcritas, notas de campo, imágenes y notas de audio al software Atlas-ti para categorizar, codificar y establecer relaciones entre los datos. Debido a una recolección y análisis casi paralela de datos, fueron necesarias la codificación y la categorización inductiva con el fin de reducir el volumen de los datos recopilados, ordenándolos en torno a patrones de respuesta que reflejaran los principales parámetros culturales de los actores investigados, permitiendo así estructurar el análisis profundo y materializar el conocimiento generado por esta investigación.

Este sistema categorial inicial se diseñó para ingresar los datos recolectados, así como la generación de subcategorías y categorías emergentes, permitiendo el diálogo con la pregunta de investigación. Por último, se realizó una codificación axial con la finalidad de relacionar las categorías a las subcategorías, y de esta forma lograr explicaciones más precisas y completas sobre los fenómenos investigados. 


\section{RESULTADOS}

De acuerdo con Pelli (2006), la vivienda entregada se asocia con las metas políticas que muchas veces propone la gestión pública para cumplir metas cuantitativas, limitando lo cualitativo en términos constructivos y espaciales del objeto-vivienda. En este sentido, mi planteamiento busca establecer una reflexión más allá de las funciones que debe cumplir una vivienda al brindar refugio, protección, reducir esfuerzos y molestias físicas en un espacio que se compone de volúmenes, instalaciones, barreras y soportes materiales, para indagar así por la dimensión simbólica de los propietarios. Considerando el afecto, la experiencia y los significados asociados al espacio que habitan, se buscó entender la forma en que las personas experimentan los sentidos de pertenencia y los lazos de afecto o rechazo que se construyen con relación a los espacios construidos.

Aunque la mayoría de los habitantes pasaron de tener un área promedio de $29 \mathrm{~m}^{2}$ a $45 \mathrm{~m}^{2}$, en casas autoconstruidas ubicadas en zonas de alto riesgo, muchos de ellos expresaron dificultades con el nuevo espacio para acomodar sus muebles, enseres y electrodomésticos. A pesar de que en su antigua vivienda el espacio era en muchos casos reducido y sin divisiones, las personas tenían una sensación de mayor amplitud, debido a la ubicación de todos sus enseres domésticos en un mismo sitio, mientras que en estos apartamentos han tenido que ajustar todas sus materialidades a un lugar que se encuentra separado para cada actividad. Independiente de que el espacio esté concebido con áreas delimitadas para que las personas lleven a cabo diferentes acciones, mis observaciones mostraron que los habitantes utilizan de forma híbrida, multifuncional y flexible un solo espacio donde permanecen gran parte del tiempo: la habitación.

Sobre la subutilización de algunos espacios de la nueva vivienda como la sala o el comedor, o la inconformidad por el espacio reducido en el lavadero de ropas, hace que muchos habitantes perciban de forma negativa el tamaño de la vivienda, la distribución y los acabados; mientras que otras personas se sienten frustradas ante la imposibilidad de tener un segundo piso en su casa. Para construir o compartir espacio con sus familiares, tal y como lo hacían cuando habitaban en la vivienda informal, las familias podían construir y crecer siempre hacia arriba. Sin la posibilidad de obtener dinero a través del aire (segundo piso para construir), muchas de estas familias manifiestan un sentimiento asociado con la frustración, debido a que la mayoría de su patrimonio dependía de la antigua vivienda, mientras que ahora, las posibilidades de crecer y de entregar un techo a sus hijos y nietos, desaparece con la tenencia de estos apartamentos. Con relación al uso informal del suelo que se evidencia en este tipo de construcciones, Escallón (2011) dice que la posibilidad de su uso intensivo sin la mediación del Estado, puede ser vista como una libertad para aquel que posee una propiedad informal, bien sea de un lote o de una edificación. Esta externalidad, según la autora, es una libertad urbanística y constructiva con tendencia a la verticalidad informal que, a su vez, se convierte en una ventaja para los asentamientos informales frente al mercado formal del suelo. Provenir del habitar en la quebrada con viviendas autoconstruidas y en muchos casos en zona de riesgo, no era un impedimento para que estas personas construyeran sobre su vivienda una nueva para sus hijos, y los hijos de sus hijos, lo que era para muchos, quizás, el único patrimonio del que podían disponer para alquilar o vender.
Otro aspecto relacionado con los métodos de subsistencia de esta comunidad, tiene que ver con los habitantes que recurren al subarriendo de una o dos habitaciones en sus apartamentos, para obtener ingresos económicos. Para llevar esto a cabo las familias deben reducir su espacio, alojándose todos en una misma habitación y en estado de hacinamiento, tal y como lo hacían cuando vivían en la informalidad. Aunque el subarriendo no es un fenómeno exclusivo de este proyecto habitacional y existe en otras ciudades y países con diferentes condiciones socioeconómicas, esta situación es quizá, el único activo en muchos hogares con recursos de subsistencia limitados.

Otras situaciones asociadas a la nueva configuración del espacio y las diferentes apropiaciones e interpretaciones que le asignan los moradores a su vivienda, se relaciona con los usos que se mezclan entre el espacio privado y el público. En este caso, los niños que habitan en los edificios permanecen la mayoría del tiempo en los sitios más próximos a su vivienda y no en los lugares que se destinaron para estas actividades como parques bolsillo, senderos y plazoletas ubicados en los bajos de los bloques $3,5,7,8$ y 12 (ver imagen 1).

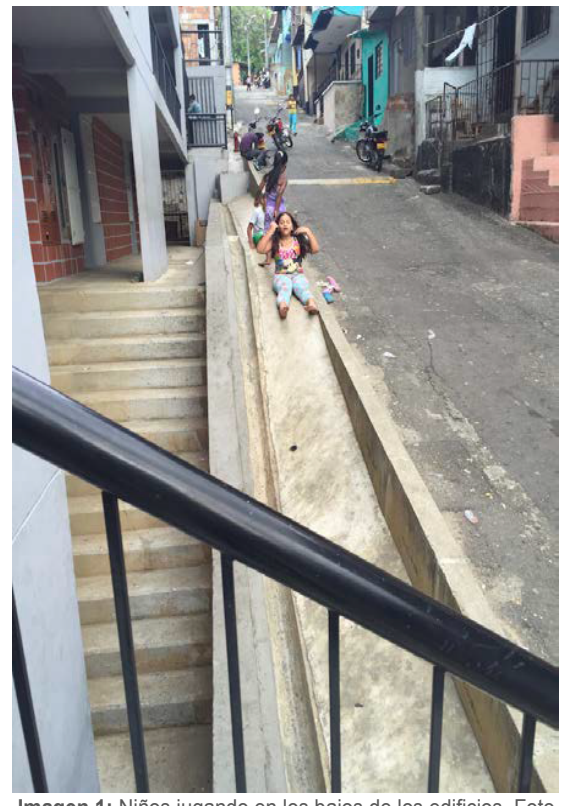

Imagen 1: Niños jugando en los bajos de los edificios. Foto tomada por la autora.

Algo similar ocurre con las mujeres y adultos mayores, quienes a diferentes horas del día se ubican en los corredores, escaleras y entradas de los bloques para conversar con otros vecinos, recibir el sol, hablar por celular, pasar la tarde en una pequeña silla o simplemente permanecer de pie apostados sobre las barandas mirando hacia la calle, como si fueran los únicos ámbitos de socialización disponibles por fuera de la vivienda.

La falta de apropiación de la comunidad frente a la implementación de algunos espacios pensados originalmente para la socialización, se hizo más evidente 
en los bajos del bloque 13. Allí, según algunos de sus habitantes, las entidades estatales instalaron un parque infantil sobre una placa de cemento detrás del edificio, para el uso y el esparcimiento de los niños; sin embargo, el espacio ha sido utilizado por la mayoría de adultos residentes para fiestas y bailes. Bajo el pretexto de celebrar una fiesta de grado, algunos de los adultos y niños que habitan este bloque, desmontaron toda la infraestructura instalada por la Administración, lanzándola a la quebrada (ver imagen 2).

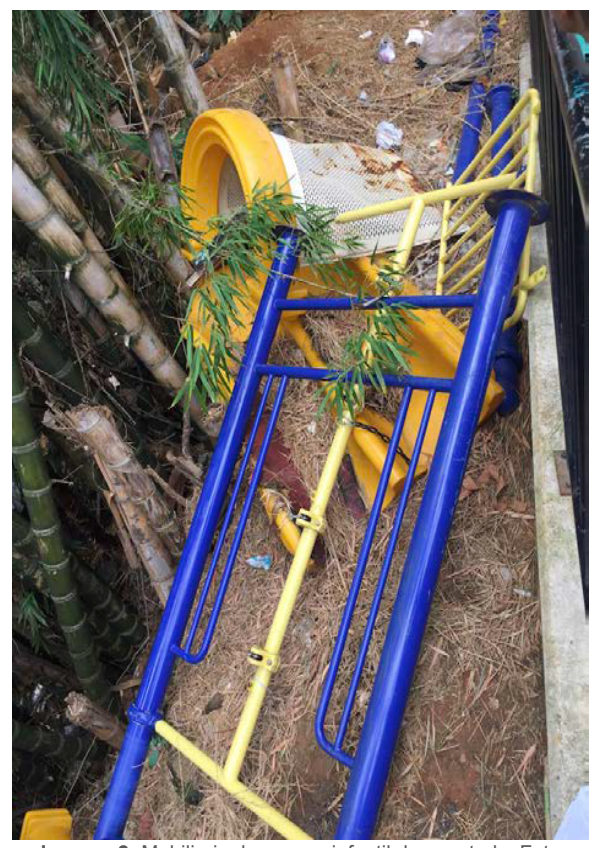

Imagen 2: Mobiliario de parque infantil desmontado. Foto tomada por la autora.

Si bien es cierto que este tipo de espacios pueden resultar más benéficos para la población infantil, en términos de ocio y esparcimiento, es un hecho que la comunidad adulta fue la que estableció el tipo de espacios necesitaban, para llevar a cabo sus prácticas de socialización.

Mientras el espacio concebido pretendía generar zonas para promover actividades lúdicas como el juego, niños y adultos, no se evidencia una fuerte apropiación por estos lugares y, por el contrario, las personas deciden llevar sus prácticas de socialización, ocio y esparcimiento a las zonas intermedias que se encuentran ubicadas entre la vivienda y el espacio público, en vez de hacerlo en los parques, plazoletas y puntos para el encuentro ciudadano. Este espacio intermedio, según Chemas (2007), es un entorno que se hace próximo a la vivienda, donde el afuera y el adentro se convierten en un microhábitat para el individuo que, por medio de diferentes conductas y comportamientos, establece relaciones con un entorno como el barrio o la misma ciudad. Chemas (2007) también afirma que en la cotidianidad de estos lugares, aparecen unos límites flexibles y permeables definidos como fronteras que corresponden a unos imaginarios, en los cuales las personas conviven entre la casa y el espacio público.
En este sentido, el espacio vivido o espacio de las representaciones se manifiesta a través del rechazo o la aprobación de ciertas intervenciones espaciales como la pista de skateboarding o patinaje que se encuentra ubicada entre los bajos de los bloques 9 y 10 , construida un año después de que se entregaran estos edificios, para promover la recreación y el esparcimiento de los niños. Contrario a la ausencia de personas en los parques infantiles y plazoletas construidas, esta zona ha sido de gran aceptación por la comunidad, debido a la frecuencia con la que es visitada por los niños y adolescentes que permanecen durante varias horas del día y hasta altas horas de la noche jugando con balones, montando en patineta o en bicicleta.

Según la mayoría de los habitantes entrevistados, cuando las personas habitaban su antigua vivienda lo hacían de manera independiente, sin reglas ni normas que dictaban cómo debían comportarse o, cómo debían llevar a cabo la limpieza del hogar, mientras que, en los nuevos edificios, los límites de su casa llegan hasta la puerta de la entrada, y deben evitar transgredir las zonas comunes. En este sentido, muchas de las prácticas domésticas como limpiar el piso, las paredes o lavar la ropa, hace que las personas se apropien de manera diferente de otros espacios, estableciendo una relación con lo que se vive adentro y afuera de manera simultánea.

Fernández (2004) afirma que tanto "el espacio interior como frente a la zona común de la casa, que es el exterior [...] estará revestida de significados relativos al interior cuando se pone en relación con la calle, que, a su vez, estará significada como interior" (p. 109). De acuerdo con lo anterior, es posible entender cómo este espacio intermedio adquiere un sentido por las personas que lo delimitan y lo apropian, a través de actividades domésticas como el aseo y la limpieza para controlar tanto el espacio interior de la vivienda, como el exterior. Al exponer estas prácticas, los habitantes llevan su vivienda hasta el espacio público y al mismo tiempo jerarquizan los sitios estableciendo comportamientos de control, delimitación o resistencia, determinado por su propia cuenta, hasta donde llega su vivienda.

Otras manifestaciones de apropiación del espacio se evidencian a través de la práctica doméstica de lavado y secado de ropa. Aunque el espacio concebido tuvo en cuenta un área de ropas al lado de la cocina dentro de cada apartamento, muchos habitantes consideran que esta área es muy estrecha para secar la ropa y por esto recurren a otros espacios de la casa como la sala, el comedor, las ventanas, el balcón y, en algunos casos, los corredores y las zonas comunes de los edificios. El problema más frecuente que tienen la mayoría de las personas entrevistadas se asocia a la ausencia de lavadora. Sin la posibilidad de lavar ropa en grandes cantidades, las personas prefieren acumular suficiente ropa sucia y lavarla toda junta, independiente de que no tengan espacio suficiente para secarla después. Su principal recurso, según ellos, es aprovechar los días de sol en ventanas, balcones, barandas y zonas comunes, si así lo requieren (ver imagen 3). 


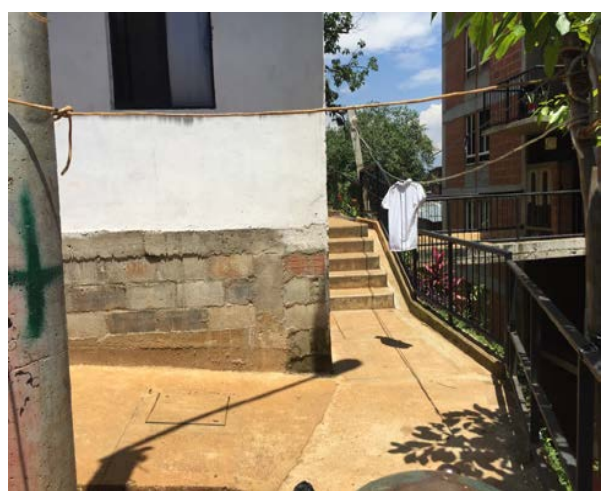

Imagen 3: Secado de ropa en zonas comunes de los edificios. Foto tomada por la autora.

A pesar de que la norma sobre el manejo de las tareas domésticas fue uno de los temas más discutidos con la comunidad receptora antes de construir y entregar los apartamentos, es evidente que estos comportamientos permanecen, aunque la Administración hubiera modificado su espacio para habitar. Independiente de los controles y el orden que buscaba establecerse a partir del espacio concebido, para que la población reasentada empezara a comportarse de manera diferente, muchas familias se resisten y desacatan las normas de convivencia desde la vivienda formal, apropiándose del espacio de diferentes maneras, en respuesta a la imposición de las reglas que antes no tenían, cuando habitaban de manera informal en la quebrada.

De acuerdo con el espacio concebido que generó un modelo de intervención urbana basado en la integración de componentes de inversión social, mejoramiento barrial físico urbanístico y de vivienda, los habitantes narran cómo estas transformaciones trajeron cambios positivos asociados a la aprobación del sector, como la disminución de homicidios y de hechos violentos; saneamiento y manejo de basuras y residuos, menor contaminación y aumento del espacio público. A pesar de la gran transformación que se dio en la zona nororiental de la ciudad, el tema asociado al cuidado y limpieza en sectores aledaños a la quebrada, el espacio público y las zonas comunes de toda la consolidación habitacional es una constante en la actualidad. En el caso de las basuras y el manejo de residuos, se ha convertido en uno de los focos de discusión y conflicto entre los habitantes, afectando la convivencia con y entre los residentes de los apartamentos y los vecinos antiguos del sector. Con la presencia de basuras, escombros y muebles que vuelven a aparecer sobre la quebrada de Juan Bobo, los senderos peatonales, los parques y el espacio público, muchos de los habitantes sienten que su barrio está volviendo a ser lo que era antes de la intervención (ver imagen 4).

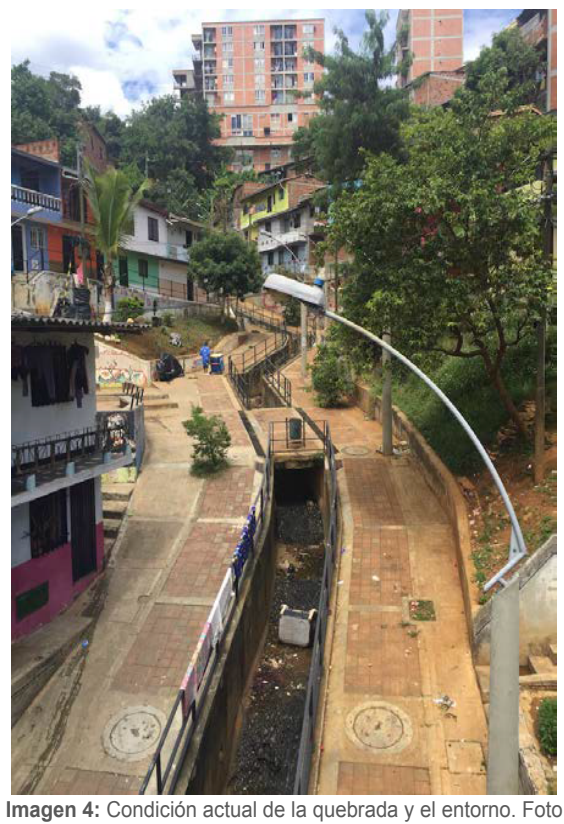
tomada por la autora.

Después de indagar sobre la forma en que perciben el cambio de vivienda y la transformación de su barrio, la gran mayoría respondió de manera positiva respecto a la implementación de las diferentes obras que incluyeron el saneamiento de la quebrada, la vivienda nueva y la generación de espacio público. No obstante, la mayor parte de la población que reconoce la transformación y mejora del sector en términos físicos y sociales afirma que, si tuviera la posibilidad de irse hacia otro lugar, lo haría debido a los problemas que les ha traído la vida en comunidad. Sin dejar de considerar las grandes transformaciones que se hicieron en este sector para solucionar problemas de hacinamiento, precariedad y violencia, es evidente el bajo nivel de aceptación de los habitantes por su nueva vivienda y el deseo de salir de ellas para volver a vivir en la informalidad, en caso de ser necesario.

A pesar de que la violencia dejó de ser una constante en este sector, los habitantes reconocen que no ha sido suficiente para generar un vínculo afectivo fuerte, con el nuevo espacio que les fue entregado. En la búsqueda sobre los significados que tiene para la población reubicada en el mismo lugar, la vida en comunidad aparecen sentimientos rechazo por la nueva vivienda y manifestaciones de resistencia, ante la imposición de nuevas conductas para habitar en los edificios, las personas responden apropiándose de otros espacios que ya no pertenecen a sus viviendas. A esto se suma el encuentro de sentimientos que se debaten entre el reconocimiento y el abandono que sienten por parte de las entidades estatales, lo que me lleva a pensar que la espacialidad influye en la vida de las personas, más allá de las cualidades físicas del mundo material. Estas manifestaciones entendidas como prácticas espaciales permiten concluir que, el habitar es una apropiación que, según Lefebvre (1970), no estará dada por la sola tenencia 
de una propiedad, sino valorada cuando se le otorgan unos afectos que le permitan a las personas interactuar con ese entorno material y desarrollar un sentimiento específico, hasta que puedan convertirlo en lugar.

\section{DISCUSIÓN}

Reconociendo el impacto positivo que trajo esta transformación urbana no solo para el sector sino, para el resto de la ciudad, se hace una reflexión sobre el papel que jugó la institucionalidad y su deseo de mejorar la calidad de vida de las personas a través de la solución de deficit habitacional. Al poner a dialogar los impactos y alcances que pueden llegar a tener este tipo de intervenciones a largo plazo, se muestran los encuentros y desencuentros que emergen cuando se transforma un espacio que buscó mejorar la calidad de vida de un grupo de personas, aparecen diferentes formas de apropiación en el espacio arquitectónico concebido, que no necesariamente responden a ese espacio concebido por instituciones como la Alcaldía de Medellín, la EDU y el ISVIMED. De acuerdo con esto, se puede decir que para muchos el ideal de una ciudad está asociado con el orden y el control, aunque en realidad, son los actores sociales de cada lugar, los que actúan con base en las lógicas de sus necesidades y de acuerdo con sus imaginarios, sobrepasando las expectativas de sus gestores.

A pesar de que la institucionalidad estableció que la gestión física y el diseño arquitectónico se podían configurar como proyectos palanca para hacer transformaciones profundas (Alcaldía de Medellín, 2011 b), los hallazgos encontrados en esta investigación dan lugar al cuestionamiento sobre los alcances que tuvo esta estrategia para impactar problemas de pobreza, exclusión, desigualdad, falta de crecimiento económico y baja gobernabilidad que caracterizaban este sector, antes de llevarse a cabo esta intervención.

En la espera de que la comunidad de Juan Bobo generara diferentes procesos sociales como la creación de un tejido social, la adopción de la formalidad y la autogestión de la sostenibilidad de espacios públicos y privados, junto con el sentido de pertenencia y afecto por el lugar, sus habitantes enfrentan una serie de responsabilidades, por habitar en la formalidad. Con sentimientos positivos y negativos frente a lo que representa la tenencia de una propiedad, las personas producen y reproducen su espacio de diferentes formas que, no necesariamente coinciden con lo que tenía establecido la institucionalidad, respecto a los modos de uso y apropiación de los espacios, los vínculos afectivos y los significados que le otorgan a su nueva vivienda. Teniendo en cuenta que este tipo de ejercicios investigativos van más allá del análisis objetual, se propone una mirada holística que abarque distintas configuraciones socioespaciales para profundizar en el conocimiento de los valores, hábitos, costumbres, imaginarios, deseos, rituales y rutinas de las personas a las cuales se dirigen los nuevos proyectos, entendiendo las necesidades que tiene cada grupo social. Si bien, la Carta Medellín ratifica la necesidad de acercarse y conocer a las comunidades para las que se va trabajar, cuando dice que "para comprender mejor la realidad y actuar sobre ella de forma pertinente es necesario considerar, también elementos de interacción social, la cultura y los valores. Y estos solo pueden aportarlo los propios ciudadanos" (Alcaldía de Medellín, 2014, p.12), no queda claro qué tipo de información de la comunidad fue tenida en cuenta para hacer este proyecto de vivienda, considerando que la intensión era mejorar su calidad de vida.

Cuando se busca incrementar el bienestar y la calidad de vida de los grupos más vulnerables a través de la transformación del espacio, es necesario pensar no solo en el presente, sino en la sostenibilidad a futuro. Si se plantean agendas a largo plazo que incluyan programas de sostenibilidad para la comunidad, es posible que éstas cuenten con los medios que les permitan resolver problemas que pueden aparecer con la adquisición de vivienda nueva como la convivencia, el desempleo, el consumo de drogas y las nuevas responsabilidades económicas. El mayor desafío que trae vincular a una comunidad a la formalidad de la ciudad, no puede quedar reducido a un proceso de transición para cada familia, sino que se deben adecuar los tiempos y las posibilidades de comprensión, asimilación y adaptación de las personas a su nueva situación. Por esto se propone abrir diversos espacios en los que la academia y el Estado trabajen juntos en procesos de desarrollo urbano y en diseño de políticas públicas en las que se apliquen conocimientos relevantes y pertinentes para la intervención y la transformación de la ciudad, en pro de los ciudadanos. Al considerar que la planeación debe servir para mejorar la tensión entre la ciudad pensada, la ciudad vivida y apropiada, se debe dirigir la mirada hacia los que van a habitar estos lugares y con esto orientar políticas, reformas institucionales y educativas sobre las características que se puedan incluir en futuras intervenciones.

A pesar de que no todos los aciertos están del mismo lado y no todos los defectos están del otro, es importante reconocer que, a medida que aparezcan más voces para transformar la realidad en la que hoy vivimos, habrá más motivos para ir de la mano con la concertación y la participación de todos los actores involucrados en este tipo de lugares. Al concluir que el nivel de satisfacción de una vivienda no se reduce solamente a la calidad y cantidad de los espacios, se recomienda para este tipo de proyectos la inclusión de la opinión de los futuros habitantes, desde las etapas tempranas del diseño y concepción de los proyectos habitacionales, implementando mecanismos de validación en términos objetivos de satisfacción, cuando reciban su vivienda. De igual forma se sugiere la realización de una evaluación posterior sobre los niveles de satisfacción subjetivos de la vivienda, una vez hayan tenido tiempo de contacto con su propiedad y entorno, para conocer los grados de empatía que se han establecido, con el fin de garantizar la vivencia en esos espacios construidos y de esta manera, trabajar con el déficit cualitativo de la vivienda de interés social.

Por último, pero no menos importante queda la recomendación de pensar en estrategias que sirvan para fomentar el tejido social, configurar lazos y establecer vínculos de confianza, solidaridad y afinidad entre los residentes para disminuir los conflictos sociales y de esta forma aportar a la convivencia entre los habitantes, considerando que la satisfacción de las necesidades relacionadas con la vivencia y la habitabilidad, no se definen únicamente con la entrega de un techo.

Cabe anotar que tanto diseñadores, urbanistas y gobiernos locales deberían aprovechar como forma de conocimiento la experiencia cotidiana y utilizarla para adelantar proyectos de carácter urbano. Los conocimientos que da conocer la cotidianidad de un lugar, pueden potencializar la participación ciudadana en la construcción de ciudad, 
fortaleciendo de esta manera los sentidos de lugar y pertenencia de las personas con su entorno. Buscar que esta clase de lugares funcionen como ejes estructurantes de la ciudad dentro del proceso de planeación y ordenación de la espacialidad urbana de Medellín, será posible, en la medida que adquieran más interés público y utilidad común.

El ideal de una ciudad organizada requiere de unos espacios ordenados y controlados, pero en la ciudad real son los actores sociales de estos lugares los que actúan con base en las lógicas de sus propias necesidades, de acuerdo con los sentidos y los imaginarios propios. Según esto, se sobrepasa la regulación del gobierno local, cuando las prácticas crean resistencias representadas en apropiaciones diferentes, o rechazo de los mismos espacios diseñados.

\section{REFERENCIAS}

ALCALDÍA DE MEDELLÍN. (2007). Plan de Desarrollo 2004-2007. Informe Final de Gestión. Recuperado de: https://www.medellin.gov.co/iri/go/km/docs/wpccontent/ Sites/Subportal\%20del\%20Ciudadano/Plan $\% 20$ de $\% 20$ Desarrollo/Secciones/Rendición\%20Pública\%20de\%20 Cuentas/Documentos/20042007/Informe\%20de\%20Gestión\%202004-2007.pdf. $(19 / 02 / 2017)$.

ALCALDÍA DE MEDELLíN. (2011a). Medellín transformación de una ciudad. Editorial multigráficas Ltda. Recuperado de: https://bit.ly/2RR3ILh

ALCALDÍA DE MEDELLÍN. (2011b). Laboratorio Medellín. Catálogo de diez practicas vivas. Mesa Editores. Recuperado de: https://bit.ly/2TOCd6

ALCALDÍA DE MEDELLín. (2014). Carta Medellin. Medellin y las ciudades para la vida. Recuperado de: https://bit.ly/2Do85sa

BÁRCENAS, Y. (2015). Las formas de habitar y su importancia en la vivienda de interés social (Tesis de maestría). Facultad de Arquitectura Escuela de Hábitat CEHAP. Universidad Nacional de Colombia Sede Medellín.

CARDONA, N. (2014). Construyendo hogar: Entre el bienestar y el vivir bien. Los impactos de la transición de vivienda de interés social en Moravia (Medellín, Colombia). (Tesis de maestría). Facultad de Ciencias Sociales. Universidad de Antioquia. Sede Medellín.

CHEMAS, M. (2007). De lo público y lo privado a la tercera zona. Impacto en el habitar urbano colombiano. Editoria Entrartes. Bogotá, Colombia.

EMPRESA DE DESARROLLO URBANO EDU. (2015). Modelo de transformación urbana. Proyecto Urbano Integral PUI- en la zona nororiental Consolidación Habitacional en la Quebrada Juan Bobo. Medellín: Alcaldía de Medellín. Recuperado https://es.slideshare.net/EDUMedellin/modelo-detransformacin-urbana-proyecto-urbano-integral-puizona-nororiental (01/04/2016).

ESCALLÓN, C. (2011). La vivienda de interés social en Colombia, principios y retos. Intervención para la apertura en el Foro Internacional: La vivienda en América Latina. Revisando estrategias. \# 35 Revista de Ingeniería. Universidad de los Andes. Bogotá D.C., Colombia. Rev.

ing. ISSN 0121-4993. Julio-diciembre de 2011, pp. 55-60

ESLAVA, A. (2017). Políticos, técnicos y comunidades. Una visión funcionalista del urbanismo social en Medellín. Fondo Editorial Universidad EAFIT. Medellín.
FERNANDEZ, P. (2004). El espíritu de la calle. Psicología política de la cultura cotidiana. México: Anthropos.

GOETZ, J y LECOMPTE, M. (1988). Etnografía y diseño cualitativo en investigación educativa. Ediciones Morata S.A. Madrid, España.

GUBA, E. G. (1978). Toward a Methodology of Naturalistic Inquiry in Educational Evaluation. Los Ângeles: UCLA.

GUBER, R. (2014). La etnografía, Método, campo y reflexividad. Siglo Veintiuno Editores. Buenos Aires Argentina.

INSTITUTO SOCIAL DE VIVIENDA Y HÁBITAT ALCALDÍA DE MEDELLÍN (ISVIMED). (2014). Carta Medellin sobre el porvenir humano de las urbes del mundo. Séptimo foro Urbano Mundial ONU-Hábitat. Medellín Corporación para el pensamiento complejo Complexus.

LEFEBVRE, H. (1970). De lo rural a lo urbano, Barcelona, Ed. Península, $1^{\text {a }}$. (edición original francesa, Ed. Anthropos, 1970).

LEFEBVRE, H. (2013). La producción del espacio. Colección Entrelíneas. Primera edición en Capitán Swing.

MARTIN, G. (2014). Medellín tragedia y resurrección. Mafia, ciudad y Estado 1975-2012. Medellín. Editorial Planeta.

MEJIA, N. (2000). El muestreo en la investigación cualitativa. En Investigaciones Sociales Año IV, número 5, 2000. Recuperado de http://revistasinvestigacion.unmsm.edu.pe/index.php/so ciales/article/view/6851/6062 12 de abril 2018.

MENA, M. (2011, 25 de julio). Habitabilidad de la vivienda de interés prioritario en el marco de la cultura. Recuperado de

http://revistas.javeriana.edu.co/index.php/cvyu/article/vi ew/5477

NARANJO, G. (1992). Medellín en zonas: monografias. Corporación Región, Medellín.

NAVARRETE, J. (2014). Por qué el renacimiento de Medellín es un modelo de Exportación. http://blogs.iadb.org/urbeyorbe/2014/04/0 5/por-que-el-renacimiento-de-medellin-es-un-modelode-exportacion/. Recuperado el 15 de febrero del 2015

PELAEZ, L. (2013). Realizaciones y sofismas del restablecimiento del hábitat en procesos por alto riesgo: Experiencias en Medellín: 1990-2010. (Tesis de maestría). Facultad de Arquitectura Escuela de Hábitat CEHAP Escuela de Hábitat. Universidad Nacional de Colombia Sede Medellín.

PELLI, V. (2007). Habitar, Participar, Pertenecer. Acceder a la vivienda- incluirse en la sociedad. Editorial Nobuko. Buenos Aires Argentina.

PÉREZ, F. (2010). Laboratorios de reconstrucción urbana: hacia una antropología de la política urbana en Colombia. Antípoda. 10., 51-84. Harvard University, Estados Unidos.

QUINTANA, A y MONTGOMERY, W. (Eds.). (2006). Metodología de investigación científica cualitativa. En Psicología: Tópicos de actualidad. Lima: UNSMSM. Recuperado de: https://es.scribd.com/doc/3634305/Metodologia-deInvestigacion-Cualitativa-A-Quintana. Mayo 72018.

SANÍN, J. (2008). Hogar en tránsito. Entre las tácticas de la malicia indígena y las estrategias de la inclusión social. Editorial Universidad Pontificia Bolivariana. Medellín Colombia.

SOJA, E. (1996). Thirdspace: Journey to Los Angeles and Other Real-and-Imagined Places, Blackwell, Londres.

SOJA, E. (2010). La perspectiva postmoderna de un geógrafo radical. Editorial Icaria. Espacios Críticos. España.

SOJA, E. (2014). En busca de la justicia espacial. TIRANT HUMANIDADES. Valencia.

STRAUSS, A. y CORBIN, J. (2002). Bases de la investigación cualitativa. Técnicas y procedimientos para desarrollar la teoría fundamentada. Editorial Universidad de Antioquia. Medellín, Colombia.

TUAN, Y. (2007). TOPOFILIA. Un estudio de las percepciones, actitudes y valores sobre el entorno. Editorial Melusina. España. 